\title{
Research on the Emotional Memory of Deity Belief in Chinese Residents for Nationalities
}

\author{
Pengsheng Zhou \\ School of Educational Science and Technology \\ Northwest Minzu University \\ Lanzhou, China
}

\begin{abstract}
In order to explore the implicit attitude of Deity belief and reasonable factors based on residents' spiritual state. With some field work and qualitative interviewing methods, the author studied the sentiment memory of Deity from residents including minority. The interviews were conducted by trained undergraduates and graduate students in psychology. With emotional statements of the infinite loyalty in Chinese residents, metaphor "psychological sustenance" was more common, and loyalty was closely related with age, occupation, religious beliefs. When heard of disrespectful sentences or saw unsuited behavior towards deity, most of the believers are positive in their emotional reactions. The emotional reaction of those unbelievers who heard disrespectful words or saw inappropriate actions is not exactly the same. The implicit attitudes of residents in various regions were reflected as inheriting the tradition, sacrificing while needed, affording comfort and so on. The education of atheism does not completely eliminate the emotional status of the deity belief, but the role of the deity in the spiritual elements is affected by the real life. Chinese residents pay close attention to the current livelihood.
\end{abstract}

Keywords-Deity belief; Emotional memory; Emotional reaction; Field work

\section{INTRODUCTION}

The belief of deity is not only related to religious belief in China, but also related to folk belief. In the folk, the belief of deity is concerned with the content of spirit, and the spirit is closely related to the ultimate goal of human beings. When material life has been developed, people began to pursue a high level of spiritual life, in which the proposition of spirit cannot be avoided, so it is necessary to explore the spirit of deity faith in-depth. The proposition of spirit involves emotional experience. The emotional memory of the deity is also indispensable in the study of the deity. The kind of memory reflects people's attitude towards the deity.

Attitude is the intrinsic structure composed of cognition, emotion and intention factor. It is the intermediary factor between the external stimulus and individual responses, and the response of the outside world is adjusted by the reaction of one's attitude. The explicit attitude is an idea that can be extracted directly from the memory, while the implicit attitude can be expressed after repeated questioning or unconsciously revealed towards things.

Previous studies have argued that belief in deity is intuitive,

Notes: "suangua" refers to prediction to the future in Chinese word, believed in majority of elder people in rural China. a natural product or byproduct of the human mind given its social context and cognitive structure. Shenhav (2012) have supported that the extent to which one believes in God may be influenced by one's more general tendency [1]. They found that individual differences in cognitive style predicted belief in God and the effect was not mediated by some demographic variables such as education level, income, etc. Their study also revealed a causal relationship over the short term: Experimentally inducing a mindset that favors intuition over reflection increases self-reported belief in God.

In Chinese traditional concept, "ghost" and "deity" are two very important ideological categories. People often use "ghost" and "deity" to represent superstition or religious ideas, and subsume the conception into their philosophical system, with "ghost" and "deity" interpretation of the movement of things. It can be stated that in their own discourse system, "ghost" and "deity" most directly reflects the relationship between faith and life.

This study intends to explore the emotional reaction to deity among residents (especially minority residents) through field work and qualitative interviews, in order to find the implicit attitude of people about the spirit of faith, and to understand resident sustenance of the spirit in the life and work. As Chen (2009) think, it is important to study the folk beliefs and folk life, which has important practical value for the process of Chinese modernization in the cohesion of the nation [2]. This study has important practical significance to explore the reasonable factors of the spiritual belief in the spiritual life of the residents, and to enhance the understanding of national cohesion.

\section{PROCEDURES AND METHODS}

The study designed three kinds of problems: one is whether he/she is loyal to the Deity, the other is whether there is emotional reaction to comply with the teachings of Deity, and the third one is how does he/she arouse emotional reaction and behavior tendency of the Deity. On the basis of the above, we design an open and semi open interview outline. The interviews were carried out by trained undergraduates and graduate students in psychology and pedagogy, and the local residents of different age groups were interviewed by convenience sampling. In 2015 and in 2016, we completed the interview task during the winter vacation time. The interview was mainly via face to face and partly through chat software 
(mainly QQ software). This design mainly has the following reasons: First, the interviewers were familiar with the local cultural tradition, and were able to skillfully use the local language to communicate; secondly, we considered the strategy to make interviews with acquaintances, including their relatives, relatives, friends and neighbors, from whom we could obtain some useful information that was not available in other cases. The interviewees were in 17 regions of 10 Provinces in China, including Hulun Buir in Inner Mongolia Province, Yanji in Jilin Province, Chengde in Hebei Province, Lanzhou, Linxia, and Wuwei in Gansu Province, Xining in Qinghai Province, Dali and Chuxiong in Yunnan Province, Liupanshui, Zunyi and Qiandongnan in Guizhou Province, Hechi in Guangxi Province, Changde, Lengshuijiang, and Xiangxi in Hunan Province, Lianyungang in Jiangsu Province. The male and female interviewees were between the ages of 21 and the age of 88 , and they were mainly public servants, migrant workers, farmers, teachers, retirees, etc.

\section{THE LOYALTY OF THE DEITY AND THE REASONS}

The premise of loyalty is to believe in a deity. The residents do not believe the existence of deity summed up the reason for his beliefs. A 46 years old man (the nationality of the interviewee is Han) said: "I am a materialist, do not believe in ghosts and deity, it does not exist and I'm not loyal, but I don't go to profane it." A 71 years old Chinese Tibetan male said the same thing: "(Deity) is a kind of ideal thing, why must be sincere?"

Some respondents did not believe in the existence of the deity orally, but expressed their implicit attitude after questioning closely. As someone said, "Do not resist", "do not violate deity", "do not believe", and "do not get angry."

Among the residents who believe in the deity, the understanding is not the same, and the metaphor of "psychological sustenance" is more common. One respondent (Yi, male, 22 years old) expressed his own idea: "in my opinion the deity belief is just a kind of my introspection, and it is not as mysterious as other people think. It is just a private belief. "Some people thought that deity is not equal to ancestors, as a Zhuang male (35 years old) said in Hechi of Guangxi Province: "We seldom believe deity. We believe our ancestors." Some residents thought that loyalty was related to work, taking a fisherman (Han, 48 years old) in Lianyungang of Jiangsu Province for example: "I should be said to be pious, and forthrightly it is because of my work. Sometimes when we encountered bad weather on the sea, we always deemed that the deity will help us to overcome difficulties. Our fishermen are used to believe deity bless."

\section{THE EMOTIONAL RESPONSES RELATED TO DEITY BELIEF}

Most of the people who did not believe in the deity were not concerned about the deity, and they would not be angry while hearing rudeness to the deity. "There is no deity. We are indifferent to worship." a Han male (77 years old) said.

Those atheistic Han residents had different emotional reactions. Some residents are directed against "disrespectful words" or "contrary to the deity". Some interviewees paid more attention to the deity itself. When hearing disrespect words or phrases of deity, a Han female (41 years old) stated: "it's a bit of a shame, because the deity is, after all, respectable." Some residents react to the nature of the deity. While knowing something contrary to the teachings from the deity, they would have a little uncomfortable feeling.

Some emotional reactions come into being because residents believe that the deity can see and hear something. Old Bai people in Chuxiong of Yunnan Province do not like to hear rudeness and disrespectful words of deity in the light of the similar reason. They believe that the deity will bless the younger generation, and bless themselves in an emergency.

Some emotional reactions come from fear of punishment from the deity. A male (62 years old) Shui people in Qiandongnan area of Guizhou Province said, "Seeing something contrary to the teachings of deity, I will be very angry. I am scared of being punished by the deity. Deity has arranged most things. Many affairs are doomed. I will be uncomfortable to refuse the oracle."

Most of the people who have faith in the deity expressed positive emotions. Most of the people who have religious beliefs did not want to hear the words of disrespect. They often say, "Please respect our faith." Catholic residents believed that God will help them and he will be angry when they make mistakes.

Some Buddhists have an implicit contradictory attitude. They sometimes are angry but later they are likewise not angry about gossip of the deity. The following is the example, and the statements are from elderly Tibetan people in Wuwei area of Gansu Province. "The society now is the one of reform and opening. Why do I be angry ah?" "We are Tibetans, relatively simple and honest. We incense kowtow to worship the deity. I do not understand why a guy curses Buddha? I will get annoyed, ah, how can I not be angry?"

\section{THE BEHAVIOR INCLINATION CORRESPONDING WITH THE EMOTION OF THE DEITY}

Normally, atheist people will not turn to the deity. No matter facing with many difficulties they do not pray. Some respondents expressed their variable ideas and behavior. "I am still young; I think I will not worship the deity. Twenty or thirty years later I may be right on the age of seventy or eighty, I may change the idea. It is hard to forecast that." a Han man (44 years old) said.

Many respondents indicated that their prayer or worship behavior is mainly to seek spiritual support and encouragement. At the same time, there are also some residents hoping for the deity while emphasizing to surmount difficulties by themselves. The implicit attitude to aspire the deity for comfort is consistent with Santayana's point of view. "Prayer, in fine, though it accomplishes nothing material, constitutes something spiritual."[3] Some respondents thought that there was little relationship between worship and belief of the deity, only following the traditional rituals. Some residents said they did not believe in the deity, but in some cases they would act as similar as worship. There are also some residents who will turn to the deity when they cannot overcome the 
difficulties with subjective efforts. An office worker in Qiandongnan area of Guizhou Province said: "I will seek divine help especially when I am cornered or painful. It is a type of psychological comfort."

Religious residents believe that worship of the deity is a sacred thing. No matter what the weather is Catholic residents will go to pray. They said: "When facing difficulties, we will seek the help of God. God will know all." The elderly Tibetan in Wuwei of Gansu Province will pray to the deity for blessing when encountered great difficulties. Some elder Tibetan people expressed a more contradictory and implicit attitude. These are the information obtained through detailed questioning. For example, a female Tibetan of 35 years old said: "When it is the time of wheat harvest, we are scared of the bad weather, such as the rainstorm. The rainstorm often destroys the crops. Then, I would quickly burn incense to kowtow and I hope the deity can stop the rain." Another Tibetan male of 62 years old detailed: "for example, (someone) is sick when digging, he will seek for suangua. If it is because the digging, (the man) has to pray. Otherwise he will be no good. As another example, someone has broken the law. He got a lenient treatment. People will say that it is because of the deity blessing, or immortal blessing. Then his family began to pray. They thought that the crime may be evil, and hope the deity blesses to the early release from prison. Sometimes, when I am sick in bed, and unable to get up, I will seek the doctor for treatment. In addition, I will seek for help of the deity or exorcism. I think that with the deity's help, I will be better."

\section{DISCUSSION}

Through field work and qualitative interviews of three kinds of questions, the author obtained the emotional memory data of the residents' belief in deity. One is to understand the loyalty of the deity; the other is to know the emotional responses by the question of residents' compliance with the teachings of the deity; still another is to interpret residents' behavior and emotional reaction corresponding worship or prayer. Through previous or after interviews and in-depth interviews, we explore the implicit attitudes of residents towards the belief in deities.

According to the general understanding of people, if an individual is no longer a believer, there is no loyalty problem. But in the interview, we found that this does not necessarily reflect the case. Although some residents stressed the premise of atheism, but when they encountered insurmountable difficulties or extreme events, they still wanted to seek help of the deity. If we did not make a detailed inquiry, we would receive only superficial information and view, rather than a deep implicit attitude.

The metaphor "sustenance" is more common. "Sometimes believe in the deity is a form of spiritual sustenance" is also a summary of some residents after the experience of serious life events. The spirit should have been placed, and the deity should have been entrusted, which is the lack of the contemporary public.

The emotional response of the residents who are believers is positive. If he complies with the oracles, he expresses a natural sense of well-being; otherwise he will be discomfort [4]. We agree with German religious scholar R.Otto (1958, 2006) without prior consultation [5]. In his opinion, when common people meet with the divine, he will form a special feeling in mind, and the feeling is mixed with two emotions of the profound respect and humility, praising and singing. "Please respect our religious belief." It is stated by most religious people, which are paid great attention by those officers related to religious work. They don't wish to hear disrespectful words. Two words "respect" and "esteem" often appear in the interview. There are some religious residents expressed an ambiguous attitude of being angry or not angry. The attitude is also in line with the current trend of social development, as a resident said: "(The society is) reform and opening up, who is still angry?" It also reflects that the attitude of religious believers has reached a generous high profile.

Previous Chinese scholars often collected studies about people's understanding of deity belief, while less current studies discussed the worship behavior of common individuals. The present study is detailed the implicit attitudes of residents such as inheriting the tradition, worshiping while needed, or pursuing comfort. Residents go to worship their ancestors or deity in order to comply with the tradition, which represents a type of missing to the death and is a euphemistic expression of seeking help of the deity. In the detailed inquiry, we found that those residents who differentiate ancestor and deity still wish that their ancestors would bless them and their descendants. Residents who are not believers will worship while needed, or behave the same action as believers to some extent. In some cases, they will turn to the deity while there are serious things or they cannot overcome the difficulties. It can be noted that, in the minds of the majority of residents, the deity is the byproduct of the need. People live and rely on themselves, and they have to seek help while needed. The attitude is pragmatic and secular. The emotional reaction also constitutes a basic motivation system, which would drive the residents to engage in worship activities and behaviors related to their beliefs. The implicit attitude to aspire the deity for comfort is consistent with Santayana's point of view (1982). "Prayer, in fine, though it accomplishes nothing material, constitutes something spiritual." [6][7] "It will not bring rain, but until rain comes it may cultivate hope and resignation and may prepare the heart for any issue, opening up a vista in which human prosperity will appear in its conditioned existence and conditional value." Prayer does not bring about any material thing, but at least it develops some spiritual aspects of human being, such as comfort, calm, and so on.

\section{SUMMARY}

Firstly, the present study found that the loyalty of the deity was related with age. Generally speaking, the older a person is, the more dependent on the deity, because he has experienced most important events. Second, it is linked to occupation. When there is a work that is not being manipulated or dangerous, people naturally take their lives to the deity, and the worship is absolutely indispensable. Thirdly, it is closely related to religious beliefs. Diverse religious believers express loyalty respectively. However, some residents strictly distinguish between the deity and ancestors. So there is such a 
statement as: "I'm not loyal to the deity, but I am devoted to ancestors". As a blind man touches an elephant, a believer always interprets loyalty on the basis of one-sided viewpoint.

We can see from the results of the interviews that many respondents do not believe in the deity. A housewife said: "What time is it? Why would anyone believe this ah? Everything depends on us. Only with my efforts and sweats I will have a good day. I will get better. It is good to behave a real life." There is a farmer said also quite rightly as the following: "Although I come from the countryside, and cannot read, I understand the meaning of the main problems. As a farmer, the most important thing is doing farm work, or farming in the land, supporting the family. I think that there are no deities and ghosts in the real world." However, there was ambiguous attitude representing more residents, such as "for the things of deity, there is no reason to disbelieve or to believe. One should not be addicted and it is not good to indulge in it." Hence it can be concluded that atheism education has not completely eliminated the emotional status of the spiritual belief. The role of the spirit or deity is affected by the real life. People pay greater attention to the present life.

\section{ACKNOWLEDGMENT}

This research was financially supported by the Special fund for undergraduate teaching construction in central university, Special fund for undergraduate teaching construction in central university ( 10019156$)$. 2017 Innovation team project "Northwest Ethnic Education Research" of the fundamental research funds for the Central Universities in "one excellent and three special" subjects" of Northwest Minzu University (Project No. 31920170096), The 2014 national education research project (project number: mjzxzd1404).

\section{REFERENCES}

[1] A.Shenhav, D. G. Rand, and J. D.Greene, "Divine intuition: Cognitive style influences belief in God", J. Exp. Psy. 141(2012), pp.423-428.

[2] Q.Chen, X.Yi, "On current research situation prospect of folk belief", N. W. Ethno National Studies, 2(2009), pp.115-123...

[3] G.Santayana, J.You, "Reason in religion" (In Chinese), Peking University Press, Beijing, 2008.

[4] S.Freud, and J. Strachey, "Introductory lectures on psycho-analysis". BMJ, 2(4594) (1963), pp.140.

[5] R.Otto, "The sacred: On the irrational in the idea of the divine and its relation towards the rational", Philosophical Alternatives, 2(2006), pp.40-55.

[6] G.Santayana, and J.You, "Reason in religion" (In Chinese), Beijing: Peking University Press. (2008), pp. 43-44.

[7] G.Santayana, Reason in religion. (pp. 24-25). New York: Dover Publications, Inc., 1982. 